\title{
Why do you ask all those questions? Supporting client profiling in financial service encounters
}

\author{
Mehmet Kilic \\ University of Zurich \\ kilic@,ifi.uzh.ch
}

\author{
Mateusz Dolata \\ University of Zurich \\ dolata@,ifi.uzh.ch
}

\author{
Gerhard Schwabe \\ University of Zurich \\ schwabe@,ifi.uzh.ch
}

\begin{abstract}
Client data is key to provide personalized services and products. Therefore, banks go through great efforts to profile their clients during financial advisory service encounters. Since traditional pen-and-paper profiling does not satisfy the banks' needs, they strive to digitalize this activity. This paper offers joint profiling as a solution: The advisor and the client jointly create a client's profile using a shared display. However, test clients provided a mixed response to a first joint profiling prototype. They wondered, why the bank needs all this information. In a second iteration, joint profiling was augmented by task awareness, i.e., linking all profiled information to the client's goal. This task aware joint profiling was far better accepted by the clients. This paper offers research insights on the role of profiling in face-to-face advisory service encounters, on its acceptance by the clients, and on design principles for digital profiling in financial service encounters.
\end{abstract}

\section{Introduction}

"Data is the oil of the 21st century" [45]. Banks have traditionally relied on collecting essential client data by profiling them during advisory sessions. As traditional means like unstructured note-taking leads to a low information quality, banks are looking for new means for collecting data during advisory sessions. Using IT in advisory sessions offers new opportunities for improving financial advice giving [35], but it remains unclear, how to best apply it for profiling during a face-to-face service encounter. Thus this paper offers an answer to the following research question: "How can IT support client profiling in financial service encounters in a way that is acceptable to the client?" We do so by providing an IT artifact that allows advisor and client to jointly engage in profiling activities. In the spirit of Design Science Re- search [26], this paper offers an abstract problem description (best stated in the words of a test client: "Why do you ask all those questions?") and two generic design principles ("joint profiling" and "task awareness") as an abstract solution to researchers and practitioners.

Banks need client data for several purposes: Most obviously, an advisor needs to understand the client's needs and situation to offer a suitable solution [12], e.g. for investing her ${ }^{1}$ money. Furthermore, banks need client data to calculate their own risks; this is primarily important in the credit and mortgage business, but banks also face regulatory and reputation risks in investment decisions [50]. Last but not least, banks need client data for their internal marketing purposes, e.g. to calculate the client value, for cross-selling, or for binding the client to the bank $[2,30]$. In the future, banks may follow the path of other industries (e.g. airline industry [27]): They may not only offer personalized services and products, but yield management may lead to personalized prizing based on a deep understanding of the clients' situation and prize sensitivity.

Consequently, clients have all reasons to be reluctant in releasing personal data to a bank, even if personal data is exchanged for a personalized product or solution [49]. Designing for information and process transparency has been proposed as a general solution approach for financial service encounters by Nussbaumer et al. [34], but their concerns were primarily around the later phase of the advisory session; they addressed profiling only in a superficial manner.

The research question describes an important class of problems and calls for principles for creating an artifact. It thus falls in the realm of Design Science Research [37]. Therefore, we engaged in collaboration with a large Swiss banking group to explore and test opportunities for an improved client profiling. The structure of this paper follows the proposal of Peffers et al. [37] for reporting Design Science Research. Thus, this paper generally follows a structure typical for DSR-re-

\footnotetext{
${ }^{1}$ For the sake of clarity, we keep referring to the client as female and to the advisor as male throughout the article.
} 
lated publications [37] and describes all of the six typical DSR activities: (1) problem identification, (2) objectives of a solution, (3) design and development, (4) demonstration, (5) evaluation, and (6) communication. The next section introduces related work on the problem and the solution. The subsequent two sections report on two design iterations. The first iteration is based on the concept of "joint profiling" and is evaluated to be a partial failure. On the basis of an analysis of the test client feedback, the second iteration proposes "task aware joint profiling". This approach was preferred by the clients to the traditional profiling. The last section then discusses the results in the light of the literature and the limitations.

\section{Related Work}

\subsection{Client profiling and its acceptance in advice giving}

A typical financial advisory session consists of three types of activities: (1) information collection, (2) information provision, and (3) recommendation [36]. Banks typically call the information collection phase "client profiling". Here the advisor gathers information about the client necessary for an elaboration of a custom-tailored solution. During the information provision, he provides all relevant information to the client, while taking client's knowledge and experience into consideration he uses sketches and brochures to make the information more comprehensible. Recommendation means that the advisor evaluates the facts discussed earlier and provides an offer that is aligned to the client's needs and situation - he conducts personalized calculations and explains possible solutions.

The phase model suggests that all later phases rely on a successful profiling phase. For investment advice, regulation (e.g. [50]) forces banks to collect data on the client's identity and on her risk preferences and capabilities. Banks frequently collect additional information e.g. on the client's employment situation, on the clients other assets and liabilities, on her budget and on her financial goals [13]. Additional profiling information includes, among others financial literacy, channel and advisory process preferences and even relational preferences, behavior, personality and life style information [13]. The latter information serves to assign clients to a client type in their client typology [4]. Banks use this information to personalize their service offerings [13], calculate the customer value [30] and optimize their own earning [13].

Sutanto et al. [47] show that some clients are willing to provide personal information for personalized offer- ings while others not. The clients express privacy-related concerns regarding lost control over the provided information and they even consider their privacy invaded when receiving personalized offerings without explicit request [cf. 25]. Overall, privacy concerns may negatively affect attitudes towards personalization and diminish the perceived benefits [cf. 25]. This is known in literature as personalization privacy paradox [3, 47]. In the specific context of online financial information, it has been shown that "the benefits of price discounts and personalized service were found to be non-effective means of gaining consumers' personal information" [49]. In other words, in online services the value of personalization seems to be lower than the value of privacy and information transparency. It is unclear, whether personalization privacy paradox can also be observed in colocated financial service encounters and if so, how it manifests itself.

In summary, based on the literature [3, 25, 47] we identify a series of factor that we expect to influence the willingness to contribute information to the profiling process during an advisory session. In this model the factors are grouped by three dimensions: trust, awareness, and motivation. In terms of trust the factors are (1) business confidence towards the institution and (2) personal trust to the advisor. In terms of awareness they are (3) awareness of what data gets collected and (4) awareness of what happens with the data after the advisory session. In terms of motivation they are (5) monetary benefits, (6) personalization benefits, and (7) regulatory reasons (if the desired service must not be conducted without particular information).

Thus banks face two inter-related problems: First, banks need reliable profiling information to fulfill their obligation to provide solid product recommendations. Clients need to be convinced to provide this information. Secondly, banks would like to collect additional client information for their own marketing purposes without raising client suspicions. The banks problems are exacerbated by a principal-agency between the bank and their advisor: Advisors regard client knowledge as their own asset and do not want to share it with the bank [43]. Banks therefore turn to digital profiling, i.e., profiling with use of IT, in order to assure that they get the high quality client information advisors deprive them of.

\subsection{Supporting Profiling in Advice giving}

Research on supporting profiling in advice giving can benefit from two different research streams: (1) other research on supporting advice giving and (2) prior research on online client profiling.

In recent years, financial service providers have started to use notebooks, tablets and tabletop-computers in co-located advisory services. If such IT is designed 
appropriately, it has been shown to enhance transparency [34], customer satisfaction [34, 35], stimulation of the client [32] and knowledge transfer [20]. If designed inappropriately, IT can decrease the quality of interaction [24], impair the client-advisor relationship [19] and lead to cognitive overload for clients and advisors [24].

The dominant research approach proposes to see advice giving as a special case of joint problem solving (starting with [46]). Thus it relies on shared workspaces $[34,42]$ for the client's problem (i.e. in investment advice: her life situation, her preferences, her risk capabilities...) and the proposed solutions (i.e. in investment advice: the investment strategy and the selected products). Researchers propose that those aspects have to be presented in a transparent manner, if the client is to really understand the ultimate (investment) decision. Transparency can be easily implemented on large screens: Each aspect is represented by a 'widget' (a kind of Window) and all widgets are simultaneously displayed, so that the relationship between all aspects can be understood (e.g. "how does the recommended investment strategy react, if I change my risk preferences?") [35]. In those settings the computer can play its strengths: the externalization of information and shared viewing affords shared understanding [42], reduces information asymmetries and thus decreases the principal agent conflict between advisor and client [31]. And simulations enhance the understanding of the financial models underlying a decision. In the case of risk models, Bradbury et al. [5] can even show that a more appropriate dynamic visualization of risk enhances risk and loss acceptance.

However, client profiling has not been in the focus of all this research. If profiling was covered at all, the researchers primed the test clients with simple profiles and only the most basic profiling data was captured [e.g. 35]. More realistic profiling has been studied in the context of online marketing and online financial services. Here, profiling is typically implemented by online questionnaires [49]. As elaborated before, user acceptance is low here, but one reason may be poor design. Automated web-based "robo-advisors" $[1,6]$ such as Wealthfront are known for its extensive questionnaires. We can only speculate that the accompanying simple simulations lead to client acceptance. However, even those robo-advisors shy away from a comprehensive client profiling compared to traditional advisory services.

Thus, despite some indications of promises and challenges as well as design ideas from neighboring research areas, it remains on open issue, how to best support client profiling in face-to-face advisory service encounters. Before we move on to a proposed solution we briefly turn to the applied methodology.

\section{Methodology}

This study follows a two-iteration approach aligned to the idea of design as a search process [37]. This offers the opportunity for deductive and inductive design knowledge inquiry [9]. Based on the literature review and in in-depth study (interviews, workshops, contextual inquiries) in a large Swiss banking group, we propose a joint profiling solution instantiated in CoProfiler 1.0 (= name of the developed prototype). We run a within-subject design experiment [28] that compares a pen-and-paper advisory session with a joint profiling session. Based on the mixed results of this experiment, we then propose a task aware joint profiling solution along with CoProfiler 2.0. Task aware joint profiling is again evaluated in a design experiment. Both steps can be seen as "design-implement-analyze" iterations in the spirit of Design Science Research (DSR).

We develop the prototypes in collaboration with the banking group. We followed a user-centered design process using methods like interviews, workshops, focus groups, and formative evaluations. The experiments use a nearly realistic setting: real advisors from the bank act as advisors, and test persons acquired through convenience sampling act as clients while following a given scenario. Both experiments were conducted in German. Each client took part in one conventional and one ITsupported advisory session in alternated order to counterbalance the order effects and retain the within-subject design. After passing through both conditions, the clients completed a questionnaire and took part in semistructured interviews. We assessed client acceptance using three instruments: 1 . Which treatment do the clients prefer? 2. What is their overall satisfaction for each treatment? and 3. How do clients perceive the overall customer orientation of each treatment?

The client preference was measured using a five-step Likert preference scale. To assess the overall satisfaction with the service, we employed the Yield Shift Theory of Satisfaction [7]. We employed the five-item fivepoint Likert scale SOCO-SHORT [48] to measure perceived customer orientation. This is a well-established and acknowledged short form of the original SOCO scale [41]. The information regarding the participants as well as results of each study are presented in the description of the studies further below.

\section{First Iteration}

\subsection{Instance Problem}

The instance problem was explored in a series of interviews and workshops with advisors and managers from 
the banking group as well as their clients. Bank managers complained that most information on the clients is hidden in the advisors' paper notebooks and conventional file folders. Neither they nor other advisors had access to this information. Advisors complained that transferring their paper-based information into the CRM system after the advisory session was too time-consuming. They also resisted translating the unstructured information from their notes to the structured CRM format. During translation some contextual information got lost and it was embarrassing for the advisor if he had forgotten to collect some information. Overall, the information in the CRM system was regarded as unreliable. First efforts to improve the information quality had failed: The bank provided the advisors with a paperbased form for profiling, 'finance house', to enable more complete information collection. Most advisors did not use this instrument in their daily practice. Thus the bank managers favored the idea of digital profiling to integrate profiling activities in the investment advice giving.

\subsection{Instance Solution: Joint Profiling}

The instance solution is based on the design principle discussed in the literature review on supporting profiling: Client and advisor share a workspace containing

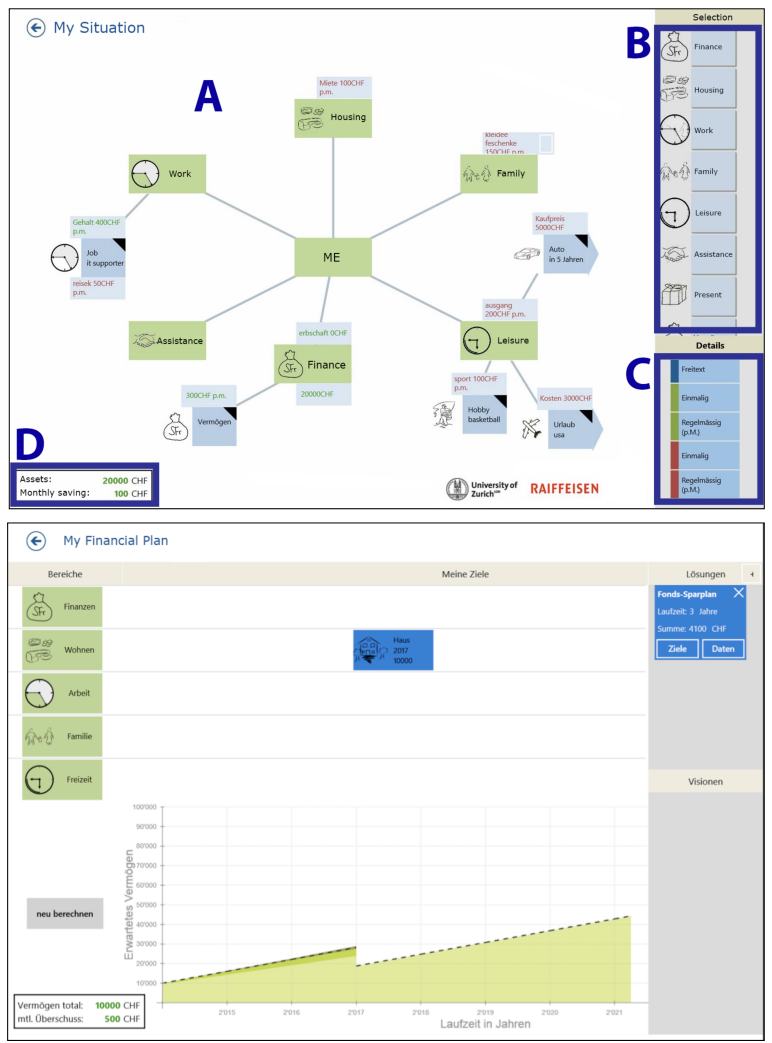

Figure 1. Profiling screen (top) and solution screen (bottom) all the profiling data. Together they develop a model of the client situation. A typical client profiling starts with the advisor asking a question regarding some area of interest (e.g. the clients budget). The client then answers this question and the advisor makes a note on the shared workspace. The workspace also contains a selection of icons representing important issues. They shall stimulate the client and the advisor. The externalized representation of the client's situation assures shared understanding and reduces information asymmetries [14]. On the fly, clients and advisors collect the information the bank needs for marketing purposes. We call this approach "joint profiling".

Joint profiling is supported by the CoProfiler 1.0. It offers two screens: The profiling screen is used for establishing shared understanding about the client's needs and goals. The solution screen presents products addressing the client's needs and goals and projects the products' impact on the client's wealth. The profiling screen, implements the concept of information resources as "note cards" that are attached to a mind map representing the situation and needs of the client. The information from the "note cards" is automatically transferred to the solution screen, which shows calculations and visualizations of solution alternatives. The solution screen is a minimal implementation of all activities that come after profiling. The screen design implements the principle what you discuss is what you see for profiling and the solution finding: when the discussion focuses on the client's needs, the profiling screen is used; when it turns to searching and evaluating a proper solution, the solution screen is used.

As illustrated in Figure 1, the screens look as follows: The center of the profiling screen contains a mind map with six default branches. Each branch represents a category of profiling typically used by our partner bank (e.g. Family, work, finance...). An ontology of information resources (note cards) relevant to the topics is shown on the right side (B). They can be drag-anddropped anywhere on the mind map. Further financial information (C) can be attached to each information item independently. The financial effect of the collected information is summarized in the wealth and monthly savings information box (D). The goals of the client are specifically marked as arrows. During the information collection the map is used to structure, summarize, control, and extend the collected information. Subsequently, the advisor and the client switch over to the solution screen (cf. Figure 1 - bottom). On this screen the goals of the client, which were identified during the needs elicitation, are prominently shown as blue note cards. The graph, which represents wealth projection, i.e., the financial future of the client if she implements the investment advice, uses the input from the first screen as starting data. 


\subsection{Evaluation}

To analyze the IT-artifact we ran a two-condition within-subject design experiment as described in the methodology section. In this particular study, the prototype was evaluated with 36 potential clients and $12 \mathrm{ex}-$ perienced financial advisors from the partner banking group in a realistic setting. To assure the privacy of the test participants, as well as to control the experiment, they were told to follow a scenario in which they receive a heritage of $60000 \mathrm{CHF}$ and want to invest the money. The evaluation took place during six days, with two advisors and six clients each day.

In the following, the results collected during the evaluation of the joint profiling prototype are presented. The supported and conventional treatments show no significant difference regarding the customer orientation. Using the SOCO-SHORT scale, the clients rated the customer orientation in the pen-and-paper treatment on average $4.12(\mathrm{SD}=0.71)$ and $4.05(\mathrm{SD}=0.64)$ in the IT treatment $(\mathrm{t}(35)=0.53, \mathrm{p}=0.60$ in a two-sided $\mathrm{t}$-test $)$. The overall satisfaction with the service does not exhibit any significant difference between the IT-supported $(\mathrm{M}=3.68, \quad \mathrm{SD}=0.73)$ and conventional $(\mathrm{M}=3.76$, $\mathrm{SD}=0.80$ ) condition. We also asked the clients to assess their satisfaction with the screens of the IT system. The satisfaction with the solution screen was significantly higher $(\mathrm{M}=3.69, \mathrm{SD}=0.76)$ than with the profiling screen $(\mathrm{M}=3.28, \mathrm{SD}=1.03)(\mathrm{t}(35)=2.13, \mathrm{p}=0.040$ in a two-sided t-test). Overall, 15 of the 36 test participants preferred the pen-and-paper (conventional) setting, 13 preferred the IT-supported one, and 8 were indifferent.

In the interviews the clients questioned the necessity of collecting all this information: "Of some of the information collected during the IT condition, you keep thinking: 'Is this really necessary now?' "They described the profiling activities as overdone and excessive: "I felt that the mind map was not only the least useful feature, but also an exaggeration. There were too many questions about me, which I did not find very relevant." Some of the test participants even wanted to break off the needs elicitation and switch to the solutionrelated activities: "I did not really see a point in sharing all this information. (...) I would have avoided this and switched to the actual core of the conversation." Some of the respondents further explained their negative attitude during the needs elicitation. They perceived the activities in the early phase as a duty of the advisor and did not see the connection to the goal: "In the IT-supported [session] I had more the feeling that the questions address things that need to be entered [in the tool] and nothing else. Clients kept wondering why the advisor asked so many questions they did not perceive as relevant for the advisory service.

\subsection{Lessons learnt}

Our first trial shows that customer-oriented profiling style cannot be directly transferred from the conventional setting to the IT-supported setting. While the boundaries between small talk and serious profiling are blurred in the conventional setting, sharing a representation of the clients profile in the IT setting makes explicit what information is really collected. And this information is not only collected by the human advisor but also by "the bank" instantiated in the IT-system. The clients view this "third actor" with more suspicion than the human advisor (equipped with paper and pencil). They want to understand, why the advisor and the system asks all those questions: For building a relationship? For future marketing? Or as a basis for a product recommendation? The solution screen actually justifies all product related question but this explanation comes too late and is nontransparent enough.

We conclude: During the information collection with the IT-artifact, the clients expected and missed the connection to the overall purpose of the encounter - receiving advice on financial issues. This occurred even though the advisor explained her particular activities, i.e., the questions she asks and why. The satisfaction level with the first and the second screen are in line with the statements made in the interviews. The clients were significantly more satisfied with the goal-oriented second screen than with the first one: it makes the mapping between the client's needs and proposed solutions more explicit. This is in line with more general studies that present relatedness to the overall goal as a supporting factor for client and employee satisfaction [23] and suggest that it should be clear [3]. Thus, we uncovered two additional antecedents for the willingness to contribute information during profiling: 1 . the perceived persistence of the data and, 2. awareness of why the information is needed.

\section{Second Iteration}

\subsection{Solution: Task aware joint profiling}

As shown above it is vital for the IT-supported customer-oriented service encounters to relate activities to the overall goal and make this relation clear to the client. In IS literature, this is known as task awareness. Promoting task awareness means to provide participants with an understanding of how their task will be completed and how current actions are linked to the overall goal $[15,16,18]$. Our second 'abstract solution' (in the sense of [26]) includes the concept of task awareness in joint profiling. Thus, we define task aware joint profiling as a joint activity, where both client and advisor know at 


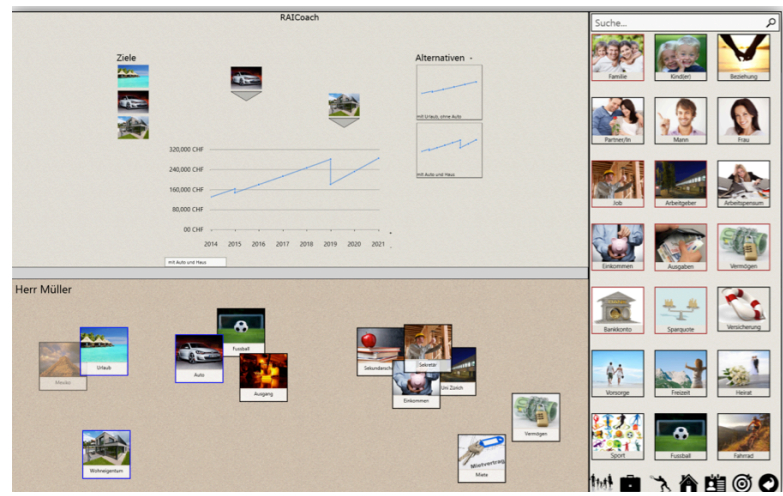

Figure 2. CoProfiler 2.0 - one screen for all activities

any moment how a single profiling activity relates to the overall task of the advisory service encounter.

Generally, awareness refers to the understanding of activities that happen in a collaborative setting that give the context to own activities $[10,11]$. Task awareness goes a step further and means: "why these activities are done" $[15,17]$. In the traditional service encounters, the advisor establishes task awareness through multiple verbal activities: he explains the advisory process and motivates his actions. For instance, when asking for family planning issues he links it with potential risks and future financial plans. Those activities seem to be very natural but form a crucial element of service encounters. The advisors failed to achieve this task awareness in the ITsupported setting applying the same techniques.

Prior research has regarded it as common sense, that in co-located, face-to-face situations information about context, activities, or emotions of others is inherently available and taken for granted $[15,18]$. Therefore, it presents the concept of awareness and, specifically, task awareness as related to distributed computer-mediated collaboration, where awareness information is not per se available. The explicit support of task awareness by means of IT in co-located settings has not caught much attention yet and has been considered primarily in technical discussions on visibility in large-size tabletop systems [38, 39] or shared access to input devices [22]. Accordingly, in the literature on tabletop systems and single display groupware, task awareness did not find its way into catalogues of design guidance [44] and was not proposed as a specific design objective $[15,16,18]$.

In distributed collaboration task awareness is primarily achieved through specific indicators permanently showing the status of a common task, the ongoing actions, actions awaiting attendance or completion, etc. [40]. However, such an explicit guidance of what needs to be done is not appropriate for advisory service encounters [34]. Clients rather require knowing, why an activity is performed. We therefore adapted Nussbaumer's [34] concept of information transparency to our purposes and linked each profiling activity to the overall purpose of the advisory service encounter. In investment advice, the overall client goal is an optimal financial future. This is typically depicted by a timeline containing the client's goals and the projected development of their wealth, i.e. wealth projection. The upper part of Figure 2 depicts an example of wealth projection. CoProfiler 2.0 implements the following design principle: Wherever possible, the client must be immediately made aware what profiling activities mean for her financial future. The visualization of wealth projection occurs on the same screen as the profiling activities (see Figure 2). Thus the effect of profiling activities is immediately reflected on the timeline. As the mind map in CoProfiler 1.0 had detrimental effects, we replaced it by unconnected note cards. Also, in order to gain screen space, we simplified the design of the profiling screen.

Thus, the CoProfiler 2.0 is implemented in just one screen, divided into three parts. The top part includes visualizations of the entire solution-relevant information. Here, the advisor explains the proposed solution and the projected wealth development. The bottom and right parts serve to collect the profiling information. Note cards in the form of images on the right side represent potential information on the client's needs and situation. These information resources can be dragged and dropped in the lower part of the screen (joint profiling area). The joint profiling area represents the current client's situation and needs: each note card receives additional description and expenses/income data. Every change in this area is immediately visualized in the solution area. For instance, when the advisor adds a particular goal in the situation area, e.g., an intention to buy a car, an adequate visualization immediately shows up in the solution area. If a value is added to a note card, e.g., the price of the car, the wealth projection is updated and reflects the impact of this expense on the financial future. If the advisor wants to focus on one of the two areas he can move the slider in the middle up or down to enlarge one area and draw the client's attention to it.

\subsection{Evaluation}

The experimental design of the second study reflects the one applied in the first study, but with a slightly different character. The first study can be considered as proof-of-value [33], i.e., one that addresses which specific value a new solution provides. The second study should be considered as proof-of-concept [33], i.e., to our best knowledge, it is the first study that introduces the notion of task awareness into face-to-face joint profiling. We aim to demonstrate the feasibility of the idea, i.e. how it can be done and with what effect. Consequently, we used a smaller sample size and rather strove for deep insights. Task aware joint profiling was evaluated with eight clients and two experienced advisors 
from the same major Swiss retail bank as before, in a realistic setting. The small number of participants only allows the observation of strong effects - as intended to demonstrate for a new concept [8]. As in the first design experiment [29], the evaluation was within-subject: every client took part in one pen-and-paper and one ITsupported advisory session. After the two advisory sessions, the clients completed a questionnaire and took part in semi-structured interviews. Furthermore, all sessions were filmed. The setting (location, tasks etc.) between both evaluations was very similar. As expected in similar setting, there was only an insignificant difference in the evaluation of the conventional treatment. Overall, five of eight test clients preferred the IT setting, one preferred the conventional one, and two were indifferent. The client satisfaction with the whole service was significantly higher in the IT than in the pen-and-paper setting $(\mathrm{t}(7)=2.89 ; \mathrm{p}=0.03$ in a two-sided t-test; pen-andpaper: $\mathrm{M}=4.08, \mathrm{SD}=0.48$; IT: $\mathrm{M}=4.49, \mathrm{SD}=0.38)$. The customer orientation in the IT setting $(\mathrm{M}=4.53$, $\mathrm{SD}=0.51)$ was evaluated significantly higher than in the conventional one $(\mathrm{M}=4.18, \quad \mathrm{SD}=0.53 ; \mathrm{t}(7)=2.82$, $\mathrm{p}=0.026$ in a two-sided $\mathrm{t}$-test; $\mathrm{Z}=2.03, \mathrm{p}=0.042$ in a Wilcoxon signed rank test).

In the interviews following the experiment, customers stated why they prefer the IT-supported condition: The comments indicate that the goal-orientation of the IT-supported encounter was clearly visible but not so in the conventional one. We got several clues that the clients noticed (and liked) the link between the information collection activities and the proposed solution. Some comments are explicit on the goal orientation of the ITsupported advisory encounter: "With IT there was more information and it was more goal-oriented." Some participants pointed out that the link between the entered information and the visualization in the solution space was constantly updated: "The visualization with IT is better, because everything is visible at a glance. It is impressive to see the effects so fast." They could see the reason why the information is collected: "In the IT setting there were immediate updates of the graphics. Therefore, I know for what the information was necessary and it was used for the calculations." They also experienced it as more transparent: "The advisor always explained for what my information was needed. With IT the usage it was more obvious." By visualizing the effects of the collected information on the solution, the participants did understand better the purpose of the information collection. Therefore, they better understood the actions of the advisor compared to the traditional setting: "In the traditional setting I had the perception that the advisor notes something and I do not know what she is doing with all this information." Some clients attribute this explicitly to the constantly updated visualization: "With IT you have everything in front of you and can anticipate the next step. In the traditional setting the advisor has everything in his mind and I cannot see it. On the screen I could better see my financial situation. You can see it directly." Another comment: "In the IT setting the solution was built stepwise. You started and recurrently watched it develop." Furthermore, test participants liked the instant and fast changes in the visualizations, which give them a more dynamic feeling: "I liked the numbers being used for the calculations so fast.". One participant preferred the pen and paper setting, because she could follow the profiling process "step-by-step".

\section{Discussion and conclusion}

A complete user profile is foundation on which subsequent advice giving builds upon. Without an adequate user profile, it is impossible to create an appropriate investment strategy and to select suitable products. Thus profiling should better be done well, particularly, since it is one of the key areas in advisory encounters, where human can still create and contribute essential value (IT systems are still bad at uncovering hidden needs [42]). In a traditional pen-and-paper setting, advisors successfully gather the profile data they personally deem necessary. However, this approach is not acceptable to banks and regulators anymore; they push for digital profiling. This is a challenge, because in contrast to other activities (that can, for instance, display interesting simulations), the immediate benefit of computer involvement in profiling is not obvious.

Based on prior research in IT-supported advice giving and collaborative technologies, we propose joint profiling as an approach to integrate digital profiling into the advisory service encounter. Joint profiling works if designed appropriately. However, its design is tricky. Profiling should be a bilateral give-and-take of information and not single-sided information acquisition by the advisor. The client offers her personal information in exchange for solution information. By observing the impact of her profiling information on her financial future, she gains a deeper understanding and is subsequently a more equal partner.

Joint profiling exacerbates information imbalances by making them visible: it creates a shared understanding not only of the client information, but also of the information imbalance. In the conventional set-up of personal note taking, the advisor can better hide profiling activities and the inherent information imbalances, e.g., behind the illusion of small talk and rapport building. Clients become more aware of what data gets collected and they see that this data gets persistent. Table 1 lists the factors we identify as influencing willingness to contribute the data during profiling in advisory services and shows that joint profiling leads to better awareness of 
what data gets collected and makes it clearer that the data can be easily made persistent. It leaves the awareness of why data is needed untouched, thus leading to the discussed imbalance.

\begin{tabular}{|c|c|c|c|}
\hline & $\begin{array}{l}\text { Factors of willingness to contribute infor- } \\
\text { mation during profiling in advisory service }\end{array}$ & $\begin{array}{l}\text { Joint } \\
\text { profiling }\end{array}$ & $\begin{array}{l}\text { Task aware } \\
\text { joint profiling }\end{array}$ \\
\hline \multirow{2}{*}{ 氖 } & Confidence towards institution & $\Rightarrow$ & $\Rightarrow$ \\
\hline & Personal trust towards advisor & $\Rightarrow$ & $\Rightarrow$ \\
\hline \multirow{4}{*}{ 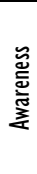 } & What data gets collected & 2 & 2 \\
\hline & What happens with the data & $\Rightarrow$ & $\Rightarrow$ \\
\hline & Why data is needed * & $\Rightarrow$ & 2 \\
\hline & Perceived data persistence * & 2 & 2 \\
\hline \multirow{3}{*}{$\begin{array}{l}\text { 흘 } \\
\text { 흘 } \\
\text { 을 }\end{array}$} & Monetary benefits & $\Rightarrow$ & $\Rightarrow$ \\
\hline & Personalization benefits & $\Rightarrow$ & $\Rightarrow$ \\
\hline & Regulatory reasons & $\Rightarrow$ & $\Rightarrow$ \\
\hline
\end{tabular}

Table 1. Changes induced by joint profiling and task aware joint profiling as compared to conventional situation with regard to factors influencing willingness to provide information during profiling in advisory services. " $\Rightarrow$ " means no change observed compared to the conventional situation, " $\boldsymbol{\nabla}$ " means increase as compared to conventional situation. "*" denotes factors identified in the first iteration.

Task awareness affords keeping an appropriate information balance in the eyes of the clients. Subjectively, it does so by immediately making explicit why information is collected and what the client gets in return. Objectively, it does so by preventing banks to collect information not related to the goals of the service encounter - advisors would run into difficulties justifying it. For the bank, the value of joint profiling rather lies in the gathering of 'dual use' information, i.e. information that has both a value for the specific advisory service encounter and other marketing activities primarily in the interest of the bank (e.g. cross-selling, customer segmentation or yield management).

A give-and-take of information perspective on client profiling is in an interesting contrast to traditional waterfall models of consecutive advice giving phases (e.g. [36]). Task aware joint profiling is an ongoing activity throughout the whole advice giving process. Whereas most profiling activities may happen at the beginning, the client may - for instance - only lay open all of her assets and liabilities later in the discussion, when she understands their impact on the investment strategy. Thus, joint profiling does not merely introduce a shared artifact into an existing process, but it rather significantly changes the process itself.

These insights contribute to several research areas: First, for research on advisory processes (e.g. [36, 46]), we offer an alternative view on client profiling: Client profiling is an ongoing activity and not a separate phase. Consequently, profiling tools should not enforce "fill- ing" them in a separate phase but rather should be accessible throughout the whole advisory service encounter. Second, for research on the acceptance of profiling we offer first insight on its application in advisory service encounters. Like in online financial profiling [47, 49], clients hesitate to provide personal information if they cannot relate it to the goal of the advisory service encounter. Interestingly, this appears to be only an issue in (computer-supported) joint profiling; the clients did not report privacy issues in the paper-and pen setting, although similar information was collected. Finally, we contribute to ongoing research on IT-supported service encounters [14, 19, 42]. We instantiate established 'joint problem solving' design ideas $[44,46]$ in joint profiling, provide insights, why joint profiling alone is not sufficient, and then propose the new approach of task aware joint profiling. The evaluation data indicates that the additional task awareness was crucial for client acceptance.

This research also offers practical insights for banks: The research data indicates that it is indeed possible to collect client profile data directly in the service encounter in a way that is accepted by the clients. Thus advisors can be relieved of their task of encounter's post-processing and documentation while the information quality can be raised. Consequently, the banks can better address their clients, fulfill regulatory requirements, and, at the same time, use this information for their own purposes. However, this new possibility has a price: each profiled information has to be justified and the need to justify limits the range of information profiled. But this may be good news - it may be a solid foundation for regaining client trust destroyed during the financial crisis.

\section{Limitations and future work}

Many limitations of the study result from the DSR approach chosen. We strove to create a comprehensive solution and not to study an isolated factor. Thus we cannot attribute the results to simple factors such as colors or pictures used in the prototypes. Moreover, we acquired the test participants - potential clients - through convenience sampling. The nearly realistic setting was chosen deliberately, but cannot be controlled as strongly as pure laboratory experiments. However, the external validity of the findings benefits from using real advisors who participated in the experiments and creating the prototypes in collaboration with external partners from the financial industry. Another limitation results from the sample sizes. The sample size for the first iteration is sufficient to uncover medium size effects and thus can be regarded as sufficient to uncover the fundamental design problem of insufficient task awareness. The sample size of the second trial only affords indications of strong effects. These strong effects were observed and thus the 
insights of the second iterations further support the insights of the first iteration and the second iteration offers a first proof of concept [33] for a possible solution. Still, the factors influencing the willingness to contribute (table 1) need to be studied and evaluated in further detail. While we have sufficient empirical evidence to propose the two additional factors "perceived data persistence" and "Why data is needed", the stability of trust factors and the motivational factors is only based on a few observations. Further research should also study the relationship between the antecedents, e.g. does (task aware) joint profiling influence trust positively or negatively?

The insights gained in this research open the door for follow-up design research: Can joint profiling be more acceptable if it is moved to more natural devices, e.g. by blending natural paper with computer interfaces [51]? How can we address other factors by means of IT? Is it, for instance, possible to reduce the persistence awareness by introducing an additional private device for the advisor? Can we enhance the motivation of the client by addressing regulatory reasons or personalization benefits? Are there other acceptable ways of digital profiling than joint profiling? Are there other (hidden) ways of profiling data during service encounters: Research from online services indicates that cheating [21] can be detected observing mouse movements. Could we also detect risk preferences or even personality features if we convince the client to directly interact with the technology during the advisory session? The issue of advisor acceptance was beyond the scope of this paper. What do they gain and loose? Do they feel happy if not only the collected client profiles but also their own profiling behavior (or traits of their own personality - if mouse movements are tracked) becomes transparent to the bank? The discussion on designing for an appropriate balance between privacy and personalized services in advisory service encounters has only just started.

\section{References}

[1] Arwas, A. et al.: Robo-Advice 2.0: The Next Generation. J. Financ. Transform. 43, 30-36 (2016).

[2] Athanasopoulou, P.: Relationship quality: a critical lit. rev. and research agenda. Eur. J. Mark. 43, 5/6 (2009).

[3] Awad, N.F., Krishnan, M.S.: The Personalization Privacy Paradox: An Empirical Evaluation of Information Transparency and the Willingness to Be Profiled Online for Personalization. MIS Q. 30, 1, 13-28 (2006).

[4] Belgum, K.D.: Who Leads at Half-time?: Three Conflicting Visions of Internet Privacy Policy. 6 RICH JL TECH 1 Symp. 1999.

[5] Bradbury, M.A. et al.: Improving Investment Decisions with Simulated Experience. Rev. Finance. (2014).
[6] Bradbury, T., others: Robo-advice is coming: What it means, who will buy it-and why. Prof. Plan. 69, 40 (2014).

[7] Briggs, R.O. et al.: The Yield Shift Theory of Satisfaction and Its Application to the IS/IT Domain. In: Integrated Series in IS. pp. 185-217 Springer (2012).

[8] Cohen, J.: Statistical power analysis for the behavioral sciences (rev. ed.). L. Erlbaum Assoc., UK (1977).

[9] Dolata, M., Schwabe, G.: Design Thinking in IS Res. Projects. Design Thinking for Innov. Springer (2016).

[10] Dourish, P., Bellotti, V.: Awareness and Coordination in Shared Workspaces. Proceedings of the 1992 ACM Conference on Computer-supported Cooperative Work. pp. 107-114 ACM, New York, NY, USA (1992).

[11] Drury, J., Williams, M.G.: A framework for role-based specification and evaluation of awareness support in synchronous collaborative applications. In: Proc. Intl. Wks. on Enabling Technologies, pp. 12-17, IEEE (2002).

[12] Gafni, A. et al.: The physician-patient encounter: The physician as a perfect agent for the patient versus the informed treatment decision-making model. Soc. Sci. Med. 47, 3, 347354 (1998).

[13] Gertz, J.D.: Purloined Personality: Consumer Profiling in Financial Services, The. San Diego Law Rev. 39, 943 (2002)

[14] Giesbrecht, T. et al.: Back in Sight, Back in Mind: Picture-Centric Support for Mobile Counseling Sessions. Proc. CSCW, Vancouver, BC, Canada (2015).

[15] Gross, T. et al.: User-Centered Awareness in ComputerSupported Cooperative Work-Systems: Structured Embedding of Findings from Social Sciences. Int. J. Hum.-Comput. Interact. 18, 3, 323-360 (2005).

[16] Gutwin, C. et al.: A Usability Study of Awareness Widgets in a Shared Workspace Groupware System. Proc. Conf. CSCW. pp. 258-267 ACM, New York, USA (1996).

[17] Gutwin, C. et al.: Support for Workspace Awareness in Educational Groupware. Proc. Conf. Computer Support for Collaborative Learning. pp. 147-156 L. Erlbaum Associates Inc., Hillsdale, NJ, USA (1995).

[18] Haines, R., Riemer, K.: The user-centered nature of awareness creation in comp.-med. communication. (2011).

[19] Heinrich, P. et al.: Enabling Relationship Building in Tabletop-supported Advisory Settings. Proc. Conf. CSCW. pp. 171-183 ACM, New York, NY, USA (2014).

[20] Heinrich, P. et al.: Microworlds as the locus of consumer education in fin. advisory serv. Proc. ICIS. (2014).

[21] Hibbeln, M. et al.: Investigating the Effect of Insurance Fraud on Mouse Usage in Human-Computer Interactions. Proc. Intl. Conf. Information Systems. (2014).

[22] Hornecker, E. et al.: Collaboration and Interference: Awareness with Mice or Touch Input. Proc. Conf. CSCW. pp. 167-176 ACM, New York, NY, USA (2008). 
[23] Judge, T.A. et al.: The job satisfaction-job performance relationship: A qualitative and quantitative review. Psychol. Bull. 127, 3, 376-407 (2001).

[24] Kilic, M. et al.: How IT-Artifacts Disturb Advice Giving-Insights from Analyzing Implicit Communication. Hawaii Intl. Conf. on System Sciences. IEEE (2016).

[25] Lee, C.H., Cranage, D.A.: Personalisation-privacy paradox: The effects of personalisation and privacy assurance on customer responses to travel Web sites. Tour. Manag. 32, 5, 987-994 (2011)

[26] Lee, J.S. et al.: Theorizing in design science research. Proc. DESRIST. Milwaukee (2011).

[27] McAfee, R.P., Te Velde, V.: Dynamic pricing in the airline industry. Forthcom. Handb. Econ. Inf. Syst. Ed TJ Hendershott Elsevier. (2006).

[28] Mettler, T. et al.: On the Use of Experiments in Design Science Research: A Proposition of an Evaluation Framework. Commun. AIS. 34, 1, 223-240 (2014).

[29] Mettler, T. et al.: On the use of experiments in design science research: a proposition of an evaluation framework. Commun. Assoc. Inf. Syst. 34, 1, 223-240 (2014).

[30] Norberg, P.A. et al.: The Privacy Paradox: Personal Information Disclosure Intentions versus Behaviors. J. Consum. Aff. 41, 1, 100-126 (2007).

[31] Novak, J.: Mine, Yours... Ours? Designing for Principalagent Collaboration in Interactive Value Creation. Proc Wirtschaftsinformatik (2009).

[32] Novak, J., Schmidt, S.: When joy matters: The importance of hedonic stimulation in collocated collaboration with large-displays. Conf. Hum.-Comp. Interaction (2009).

[33] Nunamaker, J.F. et al.: The Last Research Mile: Achieving Both Rigor and Relevance in Information Systems Research. J. Manag. Inf. Syst. 32, 3, 10-47 (2015).

[34] Nussbaumer, P. et al.: "Enforced" vs. "Casual” Transparency - Findings from IT-Supported Financial Advisory Encounters. ACM Trans Manage Inf Syst. (2012).

[35] Nussbaumer, P.: Essays on Transparent IT Support for Asymmetric Client-Advisor Encounters. Dissertation. University of Zurich, Faculty of Economics, Business Administration and Information Technology (2012).

[36] Oehler, A., Kohlert, D.: Financial Advice Giving and Taking - Where are the Market's Self-healing Powers and a Functioning Legal Framework When We Need Them? J. Consum. Policy. 32, 2, 91-116 (2009).

[37] Peffers, K. et al.: A design science research methodology for information systems research. J. Manag. Inf. Syst. 24, 3, 45-77 (2007).
[38] Pinelle, D. et al.: The Effects of Co-present Embodiments on Awareness and Collaboration in Tabletop Groupware. Proc. Graphics Interface. pp. 1-8 Canadian Information Processing Society, Toronto, Canada, (2008).

[39] Pinelle, D., Gutwin, C.: The Effects of View Portals on Performance and Awareness in Co-Located Tabletop Groupware. Proc. Conf. CSCW. pp. 195-206 ACM, New York, NY, USA (2015).

[40] Prinz, W.: NESSIE: an awareness environment for cooperative settings. Proc. European Conf. Computer Supported Cooperative Work. pp. 391-410 Springer (1999).

[41] Saxe, R., Weitz, B.A.: The SOCO scale: a measure of the customer orientation of salespeople. J. Mark. Res. 343-351 (1982).

[42] Schmidt-Rauch, S., Nussbaumer, P.: Putting Value CoCreation into Practice: A Case for Advisory Support. Proc. European Conf. on Information Systems. (2011).

[43] Schwabe, G., Nussbaumer, P.: Why IT is not being used for financial advisory. Proc. European Conf. on Information Systems. (2009).

[44] Scott, S.D. et al.: System guidelines for co-located, collaborative work on a tabletop display. Proc. Conf. ECSCW (2003).

[45] Sondergaard, P.: Big Data Fades to the Algorithm Economy, http://www.forbes.com/sites/gartnergroup/2015/08/14/big-data-fades-to-the-algorithm-economy/, (2015).

[46] Stewart, J. et al.: Single Display Groupware: A Model for co-present Collab. Proc.Conf. CHI, USA (1999).

[47] Sutanto, J. et al.: Addressing the Personalization-Privacy Paradox: An Empirical Assessment from a Field Experiment on Smartphone Users. MIS Q. 37, 4, (2013).

[48] Thomas, R.W. et al.: The selling orientation-customer orientation (SOCO) scale: a proposed short form. J. Pers. Sell. Sales Manag. 21, 1, 63-69 (2001).

[49] Ward, S. et al.: Do Incentives Matter? An Examination of On-line Privacy Concerns and Willingness to Provide Personal and Financial Information. J. Mark. Commun. 11, 1, 2140 (2005).

[50] Directive 2004/39/EC of the European Parliament and of the Council of 21 April 2004 on markets in financial instruments. (2011).

[51] Petersen, N., \& Stricker, D.: Continuous natural user interface: Reducing the gap between real and digital world. In ISMAR, 2009. 